\title{
Using Web 2.0 Applications to Increase Local Community Wellbeing
}

\author{
Rachel Keller \\ HighWire \\ Lancaster University LA1 4YW \\ r.keller@lancaster.ac.uk
}

\begin{abstract}
Typically, local communities have limited resources and technological know-how which may explain why they fail to fully exploit the features of 'web 2.0'. This is problematic because web 2.0 can increase social capital offline as well as online. Social capital contributes significantly to wellbeing. The aim of the research was to establish if a good design may significantly increase engagement for a diverse demographic typical of a local community. Diversity is critical for developing certain kinds of social capital. However 'designing for everybody' is challenging in both style and content. In the FutureVille design, an atypical range of Web 2.0 applications to those normally seen, were conjoined. The design incorporated 'status icons' as metaphors for the 'health' of the community. Evaluations by users across a wide demographic showed a high intent to use the design. Compared to a good standard community website, intent to use, was significantly higher. The FutureVille design merits further assessment with a greater number of users. This paper offers insights into engaging wider participation in Web 2.0 applications for community wellbeing and outlines challenging and potentially fruitful research avenues.
\end{abstract}

Web 2.0 applications; behavioural change; community websites; collective intelligence; digital inclusion; diversity; social capital accumulation; social innovation; wellbeing.

\section{INTRODUCTION}

Undoubtedly 'community' is what Bauman (2001) calls a 'feel good' word. As an achieved social construct of mutual ties, orientations, boundaries and obligations, how Web 2.0 technology might impact on communal wellbeing is an interesting research issue particularly as social, economic and technological changes have altered the nature, importance and influence of 'community' (Wellman, 2000). Currently several factors appear timely for a developing interest in community wellbeing: the economic and environmental climate; a national focus on community as a gateway for enhancing quality of life; growing socio-technical affordances of the internet; and digital inclusion issues that have moved beyond simple internet access to those of unequal use (Selwyn and Facer, 2007).

Current community websites generally seem concerned with mundane functions, the typical home user computing experience aimed at socialising, entertainment, shopping and accessing information. Civic and political engagement rarely feature nor does the internet as a platform for efficacy of local collective intelligence. The huge and growing commercial applications market contrasts with a paucity of community based ones.

The more immediate aim for the design was for social capital accrual, that is, increasing connections between individuals and groups, to derive benefits through increased access to resources, in particular, linking capital, which acquaints those from diverse demographics rather than reinforcing existing relationships. The problem was whether it would be possible for a design to engage a diverse demographic typical of a local community. Unless a design appeals to all demographics it is difficult to see how the benefits of diversity can be realised. This would be a challenging requirement with the danger that in designing for 'everybody', one designs for 'nobody'.

The longer term more speculative aims were to assess how web 2.0 interventions could increase 'sustainable' behaviours and provide a platform for gathering, managing and applying the collective intelligence of the community. 


\section{LITERATURE REVIEW}

\subsection{Social Capital}

Social capital can be seen as social obligations or connections between an individual and networks of other significant individuals and organisations that can be called upon for mobilisation of their own material resources, knowledge, skills or 'know-how' (Coleman et al., 2008), (Putnam et al., 1992). The more people one knows and as common outlook increases, the more social capital one possesses. Individuals have two kinds of social capital: their egocentric networks of known others and friends, and the focus of this study, that arising from their community. This latter is distinguished from the former by less reciprocity, it is determined by the social structure within the community and it may enable weaker ties or linking relationships. Reciprocity, a key part of social capital, operates online and offline. Offline effects are usually greater due to increased obligation when meeting face to face. With little expectation that people will meet in person, there is more temptation to use resources such as help, information, and support from the group without reciprocating (Walther, 1994).

Leadbeater (1997) says that 'investment in social capital is desirable because a stronger community is more able to look after itself, with stronger bonds of trust and co-operation'. Social capital is widely accepted as conferring a range of benefits supportive of well-being at micro, meso (community) and macro levels. However, social capital within a single group may not be positively related to social capital at the community level (Paxton, 1999). Warr (1987) stated 'A healthy and effective community needs a blend of different types of social capital, just as a person needs a blend of different vitamins in their diet'. As Halpern says (2005: p. 203) 'Not all forms of social capital building will lead to a positive outcome.......... community bonding social capital may have negative externalities if not balanced with bridging and linking social capital building'. The 'dark side' of social capital may be subtle or overt. For example, 'group solidarity in human communities is often purchased at the price of hostility towards out-group members' (Fukuyama, 2001).

The internet can maintain and strengthen local relations (Kavanaugh and Patterson, 2001). Deliberate interventions for social capital accrual sometimes called 'organised sociability' had more positive effect than naturally occurring networks. Importantly, these were easy to implement such as lists of neighbours and photo directories (Resnick and Shah, 2002). The Netville study (Hampton and Wellman, 2003), encouraged internet contact through an E-list of 'wired residents'. This list was one of the reasons why neighbouring flourished in
Netville but not in a similar study (Arnold et al., 2003). Granovetter (1973) showed how 'people who belong to more than one group or organization create weak social ties between groups enabling problem solving, information gathering and importing unfamiliar ideas'.

Three kinds of Social Capital are identified. Bonding capital is between people in similar situations such as family, neighbours and close friends. Bridging capital includes loose friendships and workmates. Linking capital encompasses relations between individuals and groups in different social strata in a hierarchy where power, social status and wealth are accessed by different groups (Healy et al., 2001). Woolcock (2001) extends this definition to include the capacity to leverage resources, ideas and information from formal institutions beyond the community.

This research focuses on how a community website design may enable social capital accrual both online and offline of a bridging or linking kind rather than of a bonding kind. This first key step is a design that engages and acquaints a wide demographic because, linking capital is contingent on forging relationships across diverse demographics, and bridging capital strengthening loose friendships that may develop.

Coleman (2008) found, a 'better' website led to more civic engagement. This experimental website was designed to the requirements of 'usability' in 'users wants and needs in content, navigation and appearance'. They found that effectively designed technology services enabled deliberative democracy, but that most existing services had limited potential (Wiklund, 2005).

\section{METHODS}

This was a preliminary study asking a small number of people to evaluate some web 2.0 applications. Whilst this may inevitably impact on the generalisation of the findings they may still prove useful both as 'sensitising' devices and as indicators for further research.

The aspects of the design believed to be important are those affording new face to face connections between differing demographics, and, encouraging perpetuation of relationships through shared interests and proximity (see Coleman and Festinger in the previous section and Halpern in the discussion section).

\subsection{Selecting the Users}

The users from a rural community, comprised a mixed adult demographic for age, sex, length of residence, socio-economic group, employment and health status, and internet experience. The 
community is skewed towards higher socio economic groups and an older age range.

\subsection{First Stage}

Five applications were assessed through questionnaires and semi structured interviews across 14 users. For each of the 5 applications there was a short written description. Users rated each on a 4 item likert scale of 'not use', 'possibly use', 'probably use' and 'definitely use'. Users also commented on their ratings. The applications were particularly aimed at offline social capital accrual with a particular emphasis on linking capital (the majority involve face to face meeting with people from different backgrounds) and more speculatively at 'collective intelligence' and 'sustainability' (see Figure 1). Here is a brief summary of the 5 .

YourVoice offered potential as a mouthpiece for the community and thus for aggregating 'collective intelligence' and encouraging civic engagement. Wellbeing could potentially be increased through opportunities for a wider demographic to be heard and through optimising decision making processes and follow up action. Page (2007) used a computer modelling system to demonstrate that groups with diverse skills and outlooks arrived at smart solutions more often than groups of very clever people who shared the same outlook and skills 'as long as they are organised in the right way'.

LinkUp offers opportunity to meet others with a shared interest or need. VolunteerMatch differed from traditional volunteering. First, localised provision enables more people to be involved through reducing time and travel costs. Secondly, developing new acquaintances is associated with greater social capital accumulation enabling ability to sustain relationships through proximity. The formation of ties is influenced by proximity between people as well as similar tastes or beliefs (Festinger et al., 1963) Third, organisation is improved. In Blacksburg, many groups find it easier to find leaders and other volunteer help as nearuniversal email usage reduced work for leaders to manage information and coordinate activity Kavanaugh (2003). The same benefits potentially applied to other applications.

FreeCycle involves people giving away unwanted items locally, for free. Swopshop is a local exchange trading systems swapping services for tokens rather than money.
Table 1: Estimated Wellbeing Potential ( $0=$ minimal, 1=Fair, 2 = Strong)

\begin{tabular}{|l|r|r|r|}
\hline \multirow{2}{*}{ Applications } & \multicolumn{3}{|c|}{ Estimated Outcomes } \\
\cline { 2 - 4 } & \multicolumn{1}{|c|}{$\begin{array}{l}\text { Social } \\
\text { Capital }\end{array}$} & $\begin{array}{l}\text { Collective } \\
\text { Intelligence }\end{array}$ & Sustainability \\
\hline Your Voice & 2 & 2 & 1 \\
\hline YourPhotos & 0 & 0 & 0 \\
\hline LinkUp & 1 & 1 & 1 \\
\hline Events/ Groups & 2 & 1 & 1 \\
\hline VolunteerMatch & 1 & 1 & 1 \\
\hline FreeCycle & 1 & 0 & 2 \\
\hline SwopShop & 1 & 0 & 1 \\
\hline YourHealth & 1 & 1 & 1 \\
\hline Local Services & 0 & 1 & 1 \\
\hline
\end{tabular}

It is not possible to predict the precise potential of the 5 applications of interest to enhance social capital, sustainability or collective intelligence. For example, with regards to social capital, the ratings in the following table are based on the level of interest for the applications found across demographics and the likelihood of face to face contact. Transactions for FreeCycle and SwopShop overwhelmingly involve face to face meeting to exchange services and goods. VolunteerMatch and LinkUp almost always involves meeting. YourVoice is not dependent on face to face meeting although it is anticipated that actions for community improvement arising from this application will do so.

\subsection{Second Stage}

The design was envisioned and sketched out on paper. It was informed by the questionnaire and interview feedback at stage one. This was complemented by a further literature review and analysis of 8 active community websites. The key criterion was that user testing demonstrated a high percentage showing intent to use the design, and, that this was significantly higher than comparison to a good example of a typical local community website. We hoped to achieve this through relevant content, clarity of content, navigation and expression, and, innovative features. These features were: A set of applications not normally conjoined thereby re-shaping the capability of communities; a restful, geographic theme with naturalistic colours and shape; 'at a glance' visual representations of the efficacy of each application.

Another 4 more standard applications were added giving 9 in total. These 4 were YourPhotos; YourHealth; Events and Groups and Local Services. It was felt that this gave a more complete offering than the first 5 applications and may address the concerns expressed by users about effective use of time and thus avoiding timewasters such as multiple logins. 


\subsection{Third Stage}

The design was visualised (see figure 1) along with a rudimentary build of the HomePage and the YourVoice application. Our business experience shaped our view that that naturalistic colours and shapes, with reduced information, would be preferred over standard community website designs. The style was in keeping with the theme of a tangible, physically based community.

\subsection{Fourth Stage}

We carried out user testing on 6 demographically wide ranging individuals from a nineteen year old computer science student to an eighty year old who had never used a computer. They were briefed to be candid and that any criticisms would be welcomed.

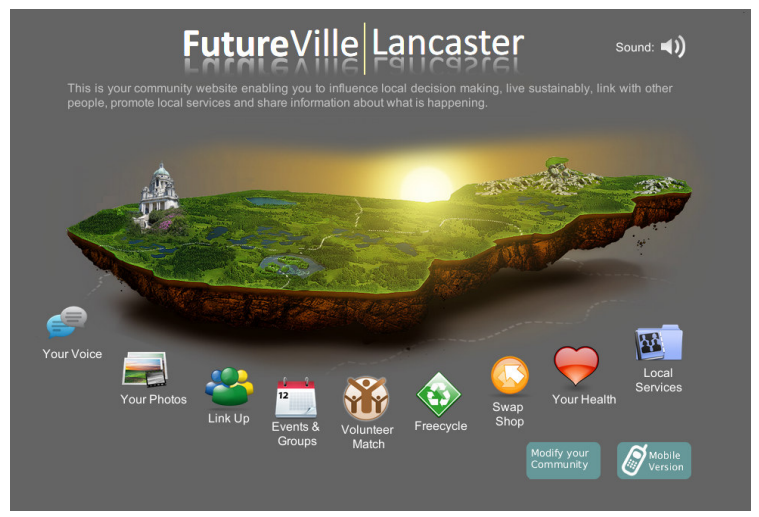

Figure 1: Homepage Design Illustrating Content and Style http://futureville.uphero.com

They had unlimited time to explore the website in whatever order they wished. Four then completed a questionnaire which took about thirty minutes. This was followed by a semi structured interview which lasted about thirty minutes. The two exceptions were the eighty year old and a middle aged person who was very nervous of using a computer. They were observed and recorded whilst they explored the website and 'spoke aloud'. This was followed by a semi-structured interview.

\section{THE DESIGN ISSUES AND RESPONSES}

Many of the web 2.0 applications were different to those normally comprising a community website. Of those applications that already existed on a national basis, such as FreeCycle, there was an issue of whether to recreate existing applications. The disadvantage of linking to existing applications was lack of continuity in the design and the need for multiple logins. These factors were key barriers to use for many users. The resolution of these issues would involve practical, legal and social issues. As the purpose of this study was to establish appetite to use the applications, and there may prove to be little appetite it was decided to reexamine these issues at a later stage.

Our business experience shaped the view that naturalistic colours and shapes, and less text, would be preferred over standard community website designs. The style was in keeping with the theme of a tangible, physically based community.

\section{RESULTS}

\subsection{Likes}

The style, clarity and content were repeatedly mentioned. Typical comments included 'clever and contemporary' and 'There is no other website like it'.....'When is it going live'? The applications were believed to be potentially very useful, being time, memory and possibly life saving (YourHealth). Typical comments included 'The idea of one stop shop idea is good'; 'very useful information all packaged into the one web site'; 'It is friendly and welcoming...... it draws you in'. All users thought the site highly usable. One user who described her computer competency as 'virtually nonexistent' was nervous about exploring the system but said 'It's clear'. She liked the idea of SwopShop, booking medical appointments online and the reminders 'things get forgotten like the village show because it happens in the summer holidays. There's too much to remember -15 things going on at once'.

\subsection{Dislikes}

One person noticed some inconsistency between the style of the different application homepages but still rated the design as 'excellent'. One comment was 'It's nice to have a front page which isn't crowded with content. But it does mean that you have to click on every page to get the updates'.

\subsection{Status Icons}

There was cautious interest in the status icons with comments such as 'quite useful' or 'I like the idea'.

\subsection{Comparison of the Two Sites}


The comparison site was determined by choosing 8 other community websites. Then two selectors both independently rated 'Dorchester People' as the best choice from the 8 in features and style.

FutureVille ratings were 5 'excellent' and 1 'good'. The comparison site had 4 'average', 1 'good' and 1 'excellent'. The user preferring the comparison site thought FutureVille 'modern, clear and eye catching' and the comparison site style was 'run of the mill'. She rated the comparison site 'excellent' as it had a lot of homepage information accessed by a long scroll down. FutureVille didn't. Comments about the comparison site were 'busy page, unexciting graphics' and 'conventional, too text heavy', 'this is a young person's website' (user in their 30's). 'It's not friendly and accessible' and 'similar to 'all other' websites'. The nineteen year old, computer science student rated FutureVille as 'excellent ......does everything that a community site should do, and that's good enough for me'

\subsection{Comments on the 9 Applications}

All the applications were thought useful although there was a distinction between 'useful to self' and useful for others. LinkUp and YourPhotos was the least popular. Most people thought LinkUp would be useful for newcomers to an area although some established users could see the benefits and intended using the application. For the digitally challenged, 'YourHealth' and 'Events and Groups' were the most appealing. This was perhaps not surprising as they are quite tangible and familiar concepts. Not everyone filled in every answer so that totals and percentages don't exactly equate.

\subsubsection{YourVoice}

Initial user testing showed over 90\% (11 out of 12 of those responding) said they would possibly, probably or definitely use YourVoice. Final user testing were primarily 'possibly/probably use'. Comments included 'It's a good forum to express your ideas. I might chat to a friend but that is not going to make things happen. Sometimes things happen without it going through the community.....it goes through the committee rather than grass roots'. The digitally competent were wary 'I'm cynical what such forums/votes can achieve'... 'if critical mass ...... could become a voice to be listened to by those in power such as 'Mumsnet'.

\subsubsection{Your Photos}

This appealed more to younger users.

\subsubsection{LinkUp}

This application was widely perceived as most relevant to newcomers to an area, however those people already established did express a tentative 'possibly use' and comments included 'great idea to tap into local interest groups or start up your own.

\subsubsection{Events and Groups}

This application had the highest intent to use 'It would be great to have a one stop shop for local events' and 'essential for anyone expanding their range of hobbies or moving into the area'.

\subsubsection{VolunteerMatch}

The main barrier to use was lack of time rather than lack of interest. However this result was perhaps skewed by users thinking of themselves as 'givers' rather than 'receivers' of voluntary help.

\subsubsection{FreeCycle}

This appealed to both givers and receivers and across socio-economic groups. It appealed on economic, time-saving, environmental and sentimental grounds. FreeCycle had motivated one user to find something similar (albeit not local) 'l've been wasting hours trying to find second-hand goods in the region with little luck'. This research had led to her getting in touch with FreeCycle and got everything she needed to furnish a house.

\subsubsection{SwopShop}

This had the widest spread of reaction. Comments ranged from 'wouldn't use' to 'definitely use'. Those people with prior experience had found it beneficial. Reservations included concern about being able to reciprocate and time issues 'Too many bits of paper, records and obligations in my life already'

\subsubsection{YourHealth}

This had much interest from booking appointments on line, through accessing useful information, to keeping personal targets. The eighty year old was particularly interested in health information.

\subsubsection{Local Services}

Feedback was typified by 'probably' and 'definitely' use, 'very useful', 'rating feature...especially useful'.

\section{DISCUSSION}

Halpern (2005: p. 323) says there is a 'strong case for more comprehensive ICT pilot projects that connect up socially mixed, geographically dense areas...... local intranet facilities should be provided to facilitate exchanges of information and trade between households and collective community action'... 'In sum, ICT networks may have great potential to boost local social capital, provided they are 'geographically intelligent', that is, are smart enough to connect you selectively to your near neighbours; are built around natural communities; and facilitate the accumulation of collective knowledge, including reputation.'

The design was different to standard community websites in style and content. The purpose was to establish the appetite across a mixed demographic as the first step towards social capital accrual of a bridging and linking kind. This was by means of applications that would bring people into face to 
face contact with each other for purposes of interest and need. The design showed promise, thus maximising the possibility of 'Intent to Use' translating into actual use with consequent effects for social capital accrual and wellbeing.

The Status Icons were a first step of visualising data by raising awareness of the efficacy of each application and thus the 'health' of the community. The cautiously positive reaction was a possible indicator of will to further engage in local issues. This initial research necessitates further assessment on a larger sample with more dynamic content in the applications. This could be followed by assessing how 'intent to use' translates to actual use and the effect on wellbeing via assessment of social capital.

\section{CONCLUSION}

The time seems ripe for extending the number and range of community applications. Not just those taking 'remedial' action to address community problems, but, those maximising wellbeing through social capital accrual particularly of a linking and bridging kind. The research demonstrated that a design appealing to a wide demographic was possible. It also demonstrated that both style and content could significantly impact on 'intent to use' the applications. Tentative interest in the 'status icons' as visual representations of the efficacy of each application, may prove a useful indicator of community wellbeing and a motivational tool for behavioural change.

\section{REFERENCES}

Arnold, M., Gibbs, M. R. \& Wright, P. (2003) Intranets and Local Community:'Yes, an intranet is all very well, but do we still get free beer and a barbeque?'. In: Huysman, M., Wenger, E. \& Wulf, V. (eds.) Communities and technologies. Kluwer, Dordrecht.

Bauman, Z. (2001) Community : seeking safety in an insecure world. Polity, Oxford.

Coleman, R., Lieber, P., Mendelson, A. \& Kurpius, D. (2008) Public life and the internet: if you build a better website, will citizens become engaged? New Media \& Society, 179-201.

Festinger, L., Back, K. W. \& Schachter, S. (1963) Social pressures in informal groups : a study of human factors in housing. Tavistock, London.

Fukuyama, F. (2001) Social capital, civil society and development. Third World Quarterly, 22, 7-20.

Granovetter, M. S. (1973) Strength of weak ties. American Journal of Sociology, 1360-1380.

Halpern, D. (2005) Social capital. Polity, Cambridge.

Hampton, K. \& Wellman, B. (2003) Neighboring in Netville: How the Internet Supports Community and
Social Capital in a Wired Suburb. City \& Community, 2, 277-311.

Healy, T., Côté, S., Helliwell, J. F., Field, S., Centre for Educational Research And, I. \& Organisation for Economic Co-Operation And, D. (2001) The wellbeing of nations : the role of human and social capital. Organisation for Economic Co-operation and Development, Paris.

Kavanaugh, A., Reese, D. D., Carroll, J. M. \& Rosson, M. B. (2003) Weak ties in networked communities. In: Huysman, M., Wenger, E. \& Wulf, V. (eds.) Communities and technologies: proceedings of the first International Conference on Communities and Technologies, C \& T 2003. Kluwer, Dordrecht ; Boston.

Kavanaugh, A. L. \& Patterson, S. J. (2001) The impact of community computer networks on social capital and community involvement. American Behavioral Scientist, 45, 496-509.

Leadbeater, C. \& Demos. (1997) The rise of the social entrepreneur. Demos, London.

Page, S. E. (2007) The Difference : How the power of diversity makes better groups, Firms, Schools and Societies. Princeton University Press.

Paxton, P. (1999) Is Social Capital Declining in the United States? A Multiple Indicator Assessment. The American Journal of Sociology, 105, 88-127.

Putnam, R. D., Leonardi, R. \& Nanetti, R. Y. (1992) Making democracy work : civil traditions in modern Italy. Princeton University Press, Princeton.

Resnick, P. \& Shah, V. (2002) Photo Directories: A Tool for Organizing Sociability in Neighborhoods and Organizations. Working paper.http://www.si.umich.edu/\%E2\%88\%BCpresni ck/papers/whothat/WhoThat021303.\%20pdf (retrieved 27 October 2010).

Selwyn, N. \& Facer, K. (2007) Beyond the digital divide : rethinking digital inclusion for the 21st century. Futurelab, Bristol.

Walther, J. (1994) Anticipated ongoing interaction versus channel effects on relational communication in computer mediated interaction. Human Communication Research, 473-501.

Warr, P. B. (1987) Work, unemployment, and mental health. Clarendon Press, Oxford.

Wellman, B. (2000) From little boxes to loosely bounded networks: the privatization and domestication of community. In: Abu-Lughod, J. L. (ed.) Sociology for the 21st Century: Continuities and cutting edges. University of Chicago Press, Chicago.

Wiklund, H. (2005) A Habermasian analysis of the deliberative democratic potential of ICT-enabled services in Swedish municipalities. New Media \& Society, 701-723.

Woolcock, M. (2001) The place of social capital in understanding social and economic outcomes. Canadian Journal of Policy Research, 2, 11-17. 